\title{
SOA Oriented Web Services Operational Mechanism
}

\author{
Meiyun Zuo and Bei Wu \\ School of Information, Renmin University of China, Beijing 100872, P.R. China \\ zuomeiyun@263.net wubeiwb@gmail.com
}

\begin{abstract}
SOA is a very important guiding theory in constructing information systems recently, the design granularity of information systems will gradually evolve from module to component. At first, this paper shows a SOA oriented information system architecture based on web services. Then it points out that getting web services reasonably and legally is the primary problem in the process of this architecture's realization. According to the different managers of web services, this paper proposes three possible operational mechanisms of web services: (1) Web Service predominant characteristic mechanism guided by large enterprises, (2) Web Services portal mechanism guided by industrial category, (3) Web Service Uniform Alliance (WSUA) mechanism. These three mechanisms may exist and compete with each other at the same time. And the authors think that the ideal operational mechanism is to build a Web Service Uniform Alliance from the perspective of utilizing and saving global intellectual resources.
\end{abstract}

Keywords: Service-oriented architecture, Web services, Service management, Service science, Operations management

\section{INTRODUCTION}

It is very important for enterprises to respond to the market changes as quickly as they can, which also becomes an important element of their core competitiveness. However, while the business processes change rapidly, the information systems they are using are relatively fixed. Hence, the conflict becomes an annoying problem to enterprises. It is high time to discuss how to change the framework model of enterprise information systems fundamentally, and how to reconstruct a dynamic enterprise information system from the bottom layer, which will assure that the information systems will adapt to the change of business requirements. This paper proposes a SOA oriented enterprise dynamic information system architecture. Whereas we must firstly figure out how to get web services reasonably and legally before we implement this architecture. According to the different managers of web services, this paper proposes three possible operational mechanisms of web services: (1) Web Service predominant characteristic mechanism guided by large enterprises, (2) Web Services portal mechanism guided by industrial category, (3) Web Service Uniform Alliance (WSUA) mechanism.

Please use the following format when citing this chapter:

7.uo, M., Wu, B., 2007, in IFIP International Federation for Information Processing, Volume 254, Research and Practical Issues of Enterprise Information Systems II Volume 1. eds. I. Xu, Tjoa A.. Chaudhry S. (Boston: Springer), pp. 753762. 
The rest of this paper is organized as follows: Section 2 designs a SOA oriented information system architecture, Section 3 proposes three web services operational mechanisms, Section 4 is the conclusion, some ideas about future work are presented.

\section{DYNAMIC INFORMATION SYSTEM ARCHITECTURE}

\subsection{Change: a Permanent Problem in the Information Systems Application}

Nowadays, more and more enterprises adopt information systems such as ERP (Enterprise Resources Planning) to assist their daily operation works and management process. Information systems play an important role in improving enterprise efficiency, reducing business costs, optimizing business processes and increasing customer satisfaction [1].

But with the pass of time, many enterprises find that most of their running information systems can't meet the new business needs flexibly. For example, in some manufacture enterprises, since the demands of product types and structures from different customers are different, the information systems are supposed to respond to the changing business needs rapidly [2]. On the other hand, a competitive environment driven by technological change and shorter product life-cycle have created a big challenge for enterprises, which should rebuild their business processes with information technology (IT) [3]. Obviously, it asks for more agility and flexibility for the information systems.

Additionally, IT itself develops very fast. Because of the lack of universal design standards in the past, a lot of legacy systems can' $t$ access with each other. In the meantime, less and less people grasping the language of legacy systems can be found with the development of new programming language and software systems [4]. However, many enterprises having invested heavily in legacy systems want to find ways to integrate them with the newer system instead of scraping them [5].

Furthermore, a common problem when adopting package software is the issue of "misfits" [6], which means there exist the gaps between the functionality offered by the package and the requirements presented by the adopting organization.

Apparently, changing is a permanent problem in the application of information systems. The full potential of IT will be achieved only when software process and business processes are able to be integrated by using a standard process integration model [7]. Then, can we find a solution to make the systems so dynamic that they can adapt to not only the demand changing but also technical changing, and also offer some basis for the matching of these two changing? Combining with the concept of SOA, in the next part, we propose a web services based information system architecture to solve the problems we mentioned above. 


\subsection{SOA Oriented Information System Architecture}

SOA (Service Oriented Architecture) is a method to organize IT infrastructure resources rather than a certain technology essentially. With the advantages of architecture, SOA can bring the enterprise many benefits: full use of the information assets the enterprise now own; persistent business processes improvement; better integration; more agility, usability and maintainability; better support for the enterprise strategy and so forth.

SOA committed to providing application functions as services offered on the Internet (or an intranet) environment which is very distributed, heterogeneous, and dynamic. It tries to bridge the boundaries between systems and organizations. The most common form of SOA is the framework based on the web services. More and more IT companies release applications and their interfaces as web services, playing the role of service provider. And then they can construct application information systems flexibly on the basis of those web services, according to the work flow in the customer businesses [8]. Once the enterprise's core functions are modeled as web services, the question of the application system integration becomes the integration of all kinds of web services [9]. Obviously, the theme of SOA is to help enterprises get rid of the constraint from fixed solutions, and face the change of business and technique easily.

On the basis of SOA concept, we propose a SOA oriented enterprise dynamic information system architecture, which is shown in figure 1. This is only a system logic framework, neglecting the operating system, middleware application server and other factors existing in bottom layer.

As is shown in Figure 1, we divide the enterprise information system architecture into three low-coupling layers: data layer, enterprise domain model layer, application platform layer. These three layers are surely related with each other, but they keep relatively independent through certain way: the data layer and the enterprise domain model layer use object or relation mapping in decoupling, while the enterprise domain model layer and the application platform layer realize decoupling through interface invoked and separation between system development and deployment. Thus, one layer can change easily while the other layers are not affected too much.

In the middle of Figure 1, viz. the enterprise domain model layer, we can construct enterprise domain objects by using business process modeling and Object-oriented analysis method comprehensively, then expose some interfaces and deploy them as web services, which will be considered as the meta functional components of enterprise information systems. The business process modeling method can analyze enterprise functions thoroughly, abstract meta-functions from business processes as service components. The Object-oriented analysis will ensure the reusability, while the standardized technology of web services ensures easy integration. After getting the meta-function components, summarizing industry best practices and enterprise special needs, industrial standard process library of the certain industry and enterprise specific process library will be constructed respectively using workflow modeling technology. For some mature industrial processes, enterprises can build their own business processes directly by using industry process templates. Moreover, for some enterprise special processes, they can go through with a secondary assembled development. In this procedure mentioned above, all the processes are assembled 
flexibly by web services from the meta-function components library, and then deployed on the application platform, making sure that the workflows in information systems will change with business processes.

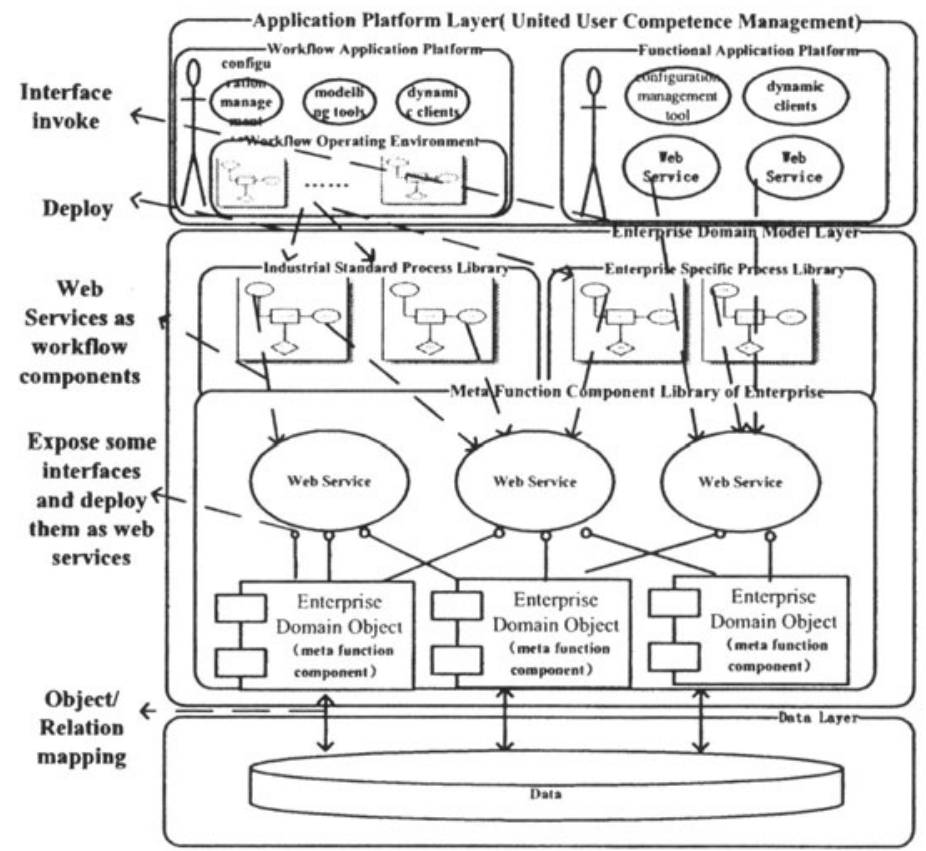

Figure 1. Enterprise Dynamic IS Architecture Model

In the top of Figure 1, there is a uniform platform. It consists of a workflow application platform and a functional application platform to meet the needs from operations related both business process and functional applications. These two platforms are administrated by uniform user authority. Only users who have the matched authority can operate on certain workflow or function. The client software is dynamically created on the application platform according to the user's actual requirements, which will keep its agility and avoid secondary development which is unnecessary.

In the process of implementation, this model can map the actual business processes of the customer enterprise quickly into its information systems by referring to the enterprise optimal business processes. After the mapping work, web services will be configured in the information systems automatically and work in the way that the enterprise wants. 


\section{THREE WEB SERVICES OPERATIONAL MECHANISMS}

However, if we want to realize the architecture showed in Section 2, how can we get web services reasonably and legally from the Internet? Since the emergence of web service concept, many software enterprises and developers in the market began to deploy and release their own application packaged as web services. Web services are all described with WSDL and registered using UDDI, whereas, how to find the right services from all kinds of similar web services for a specific user company? In another word, can there be anyone in charge of works of discriminating, classifying and managing those web services? And who is responsible for the assembly and integration works?

SLA (Service-Level Agreement) is used to not only measure the quality and cost of web services offered by service providers but also as a criterion in choosing and judging web service providers. However, SLA simply protects consumers' benefits technically [10]. Because of the expansion and virtualization of network, almost all the intellectual products on the network are facing a plight, that is, how to protect intellectual property and charge normal fees from the file-sharing network [11]. The authors believe that it is necessary to build up a set of operational mechanisms to protect the benefits of web service consumers, while web services providers' benefits will not be damaged. According to the different managers of web services, we propose three kinds of web services operational mechanisms: (1) Web Service predominant characteristic mechanism guided by large enterprises, (2) Web Services portal mechanism guided by industrial category, (3) Web Service Uniform Alliance (WSUA) mechanism.

\subsection{Web Service Predominant Characteristic Mechanism Guided by Large Enterprises}

In the IT market, there are many mainstream IT companies in each application field. Hence, we can define the mechanism in which the web services are managed by mainstream software providers as the web service predominant characteristic mechanism guided by large enterprises, shown in Figure 2. The real line arrows show a value-added process, including web services' choosing, assembly, integration and delivery. In contrast, the dotted line arrows have two meanings: firstly, they present the transportation of customers' demands, from the customers, through consultants and mainstream providers, finally to the web services providers; secondly, they show the payment transformation in this whole process (the arrows in Figure 3 and 4 have the same meaning, it will not be pointed out again later).

In this web services mechanism dominated by large enterprises, it is the mainstream software providers who have specialty in certain field that face so many web service components providers directly (including components personally developed, the same in the following parts). For example, Microsoft is one of the generic software mainstream vendors, while SAP is one of the management software mainstream vendors and the like. Certain internal evaluation and selection mechanisms on web services are made by these enterprises. Accordingly they will 
pick up qualified web services components from diverse web service providers and then assemble them into web services component products with larger granularity. Afterward, encapsulated and value added component products will be supplied to web services consumers by implementation consultants.

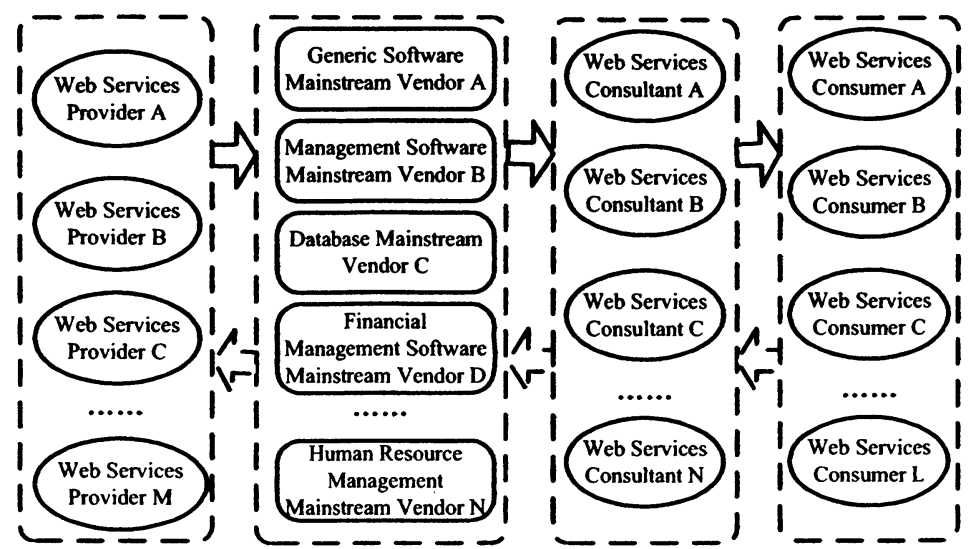

Figure 2. Web Service Predominant Characteristic Mechanism

With the pass of time, more and more web services are developed, but a majority of them are "repeated works" with similar functionality and content. There are so many similar web services that it becomes difficult for consumers to make decision in selecting them unless difference advantage can be established through different added value offered by providers. Besides, due to the diversity of the products, consumers put more emphasizes on reliability in addition to functionality. In this context, web services provided by mainstream enterprises will show their huge brand effects. Their brand advantage is much larger than the other similar products, plus professional skill and management advantage, all of the above make web services products from mainstream enterprises easy win out in the fierce competition. Generally, these mainstream enterprises can not only pick up qualified web services from various providers but also produce their own web services component products. As each of the mainstream enterprises has their own specialty field, the web service predominant characteristic mechanism guided by large enterprises is formed gradually.

In this mechanism, mainstream enterprises are responsible for choosing and evaluating web services, and then they pay for web services they have chosen, classify them and assemble new web services with larger granularity. Implementation consultants shown in the figure collect customers' demands, and buy web services with different granularities from mainstream enterprises. After assembling them and doing some secondary development works, consultants deliver these value-added web services to customers.

Certainly, if some customers have technical strength themselves, in pursuit of lower cost, they can surely cross the mainstream enterprises and consultants, and cooperate with the web service providers directly. The mainstream enterprises can also serve customers directly, without certain consultant. 


\subsection{Web Services Portal Mechanism Guided by Industrial Category}

In reality, there already exist some sorts of industrial association or organizations. Thus we can define the mechanism in which the web services are managed by industrial organization as the web services portal mechanism guided by industrial category reasonably, as is shown in Figure 3.

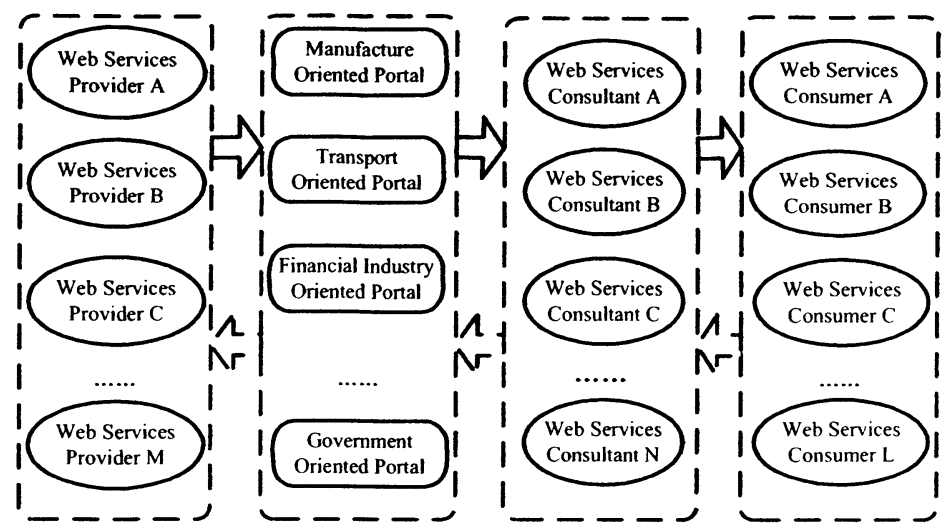

Figure 3. Web Services Portal Mechanism Guided by Industrial Category

In this kind of mechanism, according to the applications fields of the web services, the providers deploy them in different industrial portal platforms, such as manufacture oriented portal, transport oriented portal, government oriented portal and so on.

Once certain customers want to use web services, they will find the implementation consultant first. The consultant will go to the corresponding industrial portal system to find appropriate web service components they need after investigating the customer' $s$ requirement in detail. Then the consultant assembles and integrates these web services components, and supplies the customer with final product and training.

As to the formation of industrial portal, we have two proposals: (1) There may be some leader enterprises that have been developing a lot of application software in this industry for a long time. Just like what we discussed in the first mechanism, this kind of enterprises have large brand effect and mature management processes, then these industrial leader enterprises can be in charge of the management of industrial portal; or (2) In fact, it is the industrial associations that constitute, monitor and maintain the industrial criteria, so they know business processes, demands and criteria of their own industrial field better. Then, web services management institutions can also be set by industrial associations. These institutions are responsible for developing, evaluating and choosing appropriate web services for their industrial field. Undoubtedly, the industrial leader enterprises can cooperate with the industrial association to management the industrial portal. 


\subsection{Web Service Uniform Alliance (WSUA) Mechanism}

According to Cheng et al [12], their analysis result in 2006 shows that application service strategy of independent service vendors is always dominated by the service alliance, implying that providers will benefit from the increased interoperability of web services, for its low integration cost and the possibility of creating new functionalities through integrating web services. That is to say, it is better for web services providers to be joint venture or form an alliance.

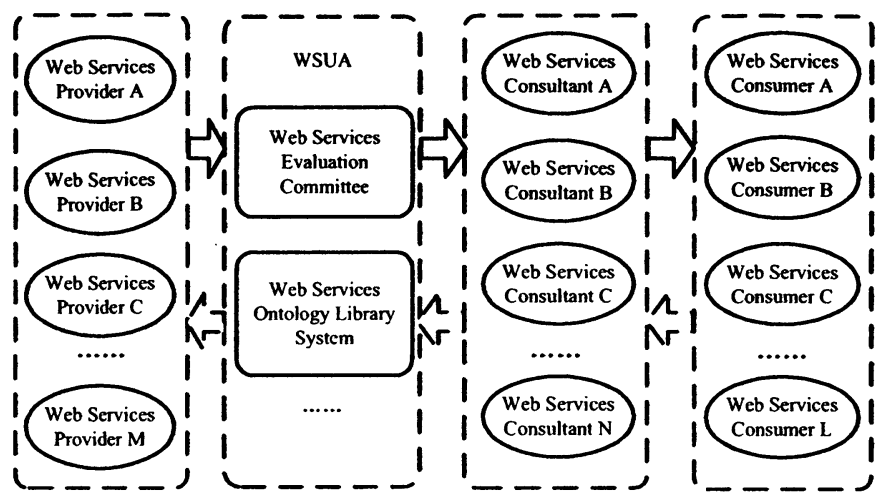

Figure 4. Web Service Uniform Alliance (WSUA) Mechanism

Actually, because there are many web services intercrossing between the industrial mechanism and the mechanism guided by mainstream enterprises, an ideal status is to form a web service uniform alliance (WSUA) which will be in charge of the management of web services in the global area. And we can define the mechanism in which the web services are managed by WSUA as the WSUA mechanism, as shown in Figure 4.

WSUA is obviously an ideal manager of the web services market. In this mechanism, all the web service providers get together via the Internet and form an alliance to choose, classify, evaluate, release and deploy web services. Furthermore, it is essentially a web service practitioners' industrial association, which is made up of web service evaluation committee, web services ontology library system [13], and etc. It is responsible for standardizing and unifying web service supply market, maintaining versions and copyrights of web services products, avoiding vicious competitions among web services providers. Figure 5 shows some responsibilities of WSUA.

Once some web services providers want to be on the WSUA provider list, they have to apply first. Unless they are committed by WSUA evaluation committee, viz., when their web service components pass the evaluation, their web service products can be added into the WSUA products list. WSUA will categorize those web service products and be in charge of their version update. 


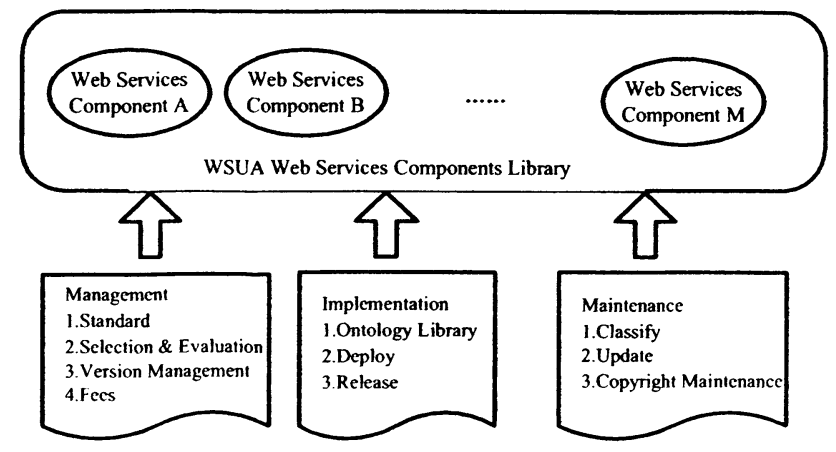

Figure 5. Descriptions of WSUA Functions

In the same way, when some user enterprises want to use web services in their new information systems, they should look for an implementation consultant at first, and then propose their requirements in detail. Once their business models are built up, the consultant will look for the corresponding web services in the WSUA ontology model system, finally assemble them into the final software product for the user enterprise. Of course, the consultant should pay the WSUA for all the web services got from it. And once the web services are updated, WSUA will be responsible for the related informing and updating works.

Some rules or declarations should be constituted to keep the related rights to the web service providers. Meanwhile, it should be noticed that the WSUA plays a very important role in offering all those web service providers a platform for fair competition and mutual cooperation. Then, vicious competitions caused by different scales will be avoided because of the agreement formed among providers.

These three mechanisms above may exist and compete with each other at the same time. Obviously, the ideal operational mechanism is to build a Web Service Uniform Alliance from the perspective of utilizing and saving global intellectual resources.

\section{CONCLUSION AND FUTURE WORK}

This paper proposes a SOA based information system architecture, and then three available web service operational mechanisms are presented according to the different managers. This will help in normalizing current web service operation. The three mechanisms are: (1) Web Service predominant characteristic mechanism guided by large enterprises, (2) Web Services portal mechanism guided by industrial category, (3) Web Service Uniform Alliance (WSUA) mechanism. The ideal operational mechanism is to build a Web Service Uniform Alliance from the perspective of utilizing and saving global intellectual resources.

However, we only presented three mechanisms and built these corresponding models. In those figures of the models, what we discussed are just the real line arrows, we didn't discuss the dotted line arrows deeply, which contains payment 
mechanism. In addition, much work about selection mechanism, evaluation mechanism and upgrade mechanism in the models needs to be discussed in the future.

\section{ACKNOWLEDGEMENTS}

This research was supported by a research grant from the Foundation of Key Laboratory of Information Management and Information Economics (Project No. F0607-42). And the first author also has a special grant from the Fok Ying Tung Education Foundation.

\section{REFERENCES}

1. D.L. Olson and F. Zhao, CIOs' perspectives of critical success factors in ERP upgrade projects, Enterprise Information Systems. Volume 1, Number 1, pp.129-138, (2007).

2. M. Holmquvist and $\mathrm{K}$. Pessi, Agility through scenario development and continuous implementation: a global aftermarket logistics case, European Journal of Information Systems. Volume 15, Number 2, pp.146-158, (2006).

3. V.L. Mitchell and R.W. Zmud, Endogenous Adaptation: The Effects of Technology Position and Planning Mode on IT-Enabled Change, Decision Sciences. Volume 37, Number 3, pp.325-355, (2006).

4. S. Chandra, J.D. Vries, J. Field, and H. Hess, Using Logical Data Models for Understanding and Transforming Legacy Business, IBM Systems Journal. Volume 45, Number 3, pp.647-655, (2006).

5. K. Furumo and A. Melcher, The Importance of Social Structure in Implementing ERP Systems: A Case Study using Adaptive Structuration Theory, Journal of Information Technology Case and Application Research. Volume 8, Number 2, pp.39-58, (2006).

6. C. Soh, S.S. Kien, and J. Tay-Yap, Enterprise resource planning: cultural fits and misfits: is ERP a universal solution? Communications of the ACM. Volume 43, Number 4, pp.47$51,(2000)$.

7. J.Y. Lee, S. Lee, K. Kim and H. Kim, A process-centric engineering web services framework, The International Journal of Advanced Manufacturing Technology. Volume 26, Number 9-10, pp.1173-1183, (2005).

8. S. Zhao and M. Zuo, A SOA Based Research on Enterprise Dynamic Information System Architecture, in Proc. of the Ist conference of China Association for Information Systems (2006), pp.295-299.

9. R. Khalaf, A. Keller, and F. Leymann, Business processes for web services: principles and applications, IBM Systems Journal. Volume 45, Number 2, pp.425-446, (2006).

10. L.J. Jin, V. Machiraju, and A. Sahai, Analysis on Service Level Agreement of Web Service, HP Laboratories Technical Report, HPL (2002).

11. R. Dannenberg, Copyright Protection for Digitally Delivered Music: A Global Affair, Intellectual Property \& Technology Law Journal. Volume 18, Number 2, pp.12-16, (2006).

12. H. Cheng, Q. Tang, and J. Zhao, Web Services and Service-Oriented Application Provisioning: An Analytical Study of Application Service Strategies, IEEE Transactions on Engineering Management. Volume 52, Number 4, pp.520-533, (2006).

13. Y. Ding and D. Fensel, Ontology Library Systems: The key for successful Ontology Reuse, in Proc.s of the 1st Semantic web working symposium (Springer-Verlag Heidelberg: Heidelberg, 2001), pp.93-112. 